Check for updates

The BMJ

Cite this as: BMJ 2021;372:n242 http://dx.doi.org/10.1136/bmj.n242 Published: 27 January 2021

\title{
Covid-19: NHS must tackle vaccine lies to improve uptake among ethnic minorities, says Stevens
}

Gareth lacobucci

The chief executive of NHS England has described "genuine and deep concern" that uptake of covid-19 vaccines may be lower among minority ethnic groups.

Simon Stevens told MPs on 27 January that, while overall vaccine uptake to date had been "fantastic," the NHS needed to combat "systematic efforts to misinform and lie" and the "longstanding mistrust" in some communities to ensure equitable distribution.

A recent poll of 2000 UK adults by the Royal Society for Public Health ${ }^{1}$ found that three quarters $(76 \%)$ of people overall would willingly have a covid vaccination-but this fell to $57 \%$ of respondents from minority ethnic backgrounds.

Speaking at the joint inquiry by the health and science select committees into lessons learnt from covid, Stevens said, "It is a genuine and deep concern, because we are seeing more vaccine hesitancy on the part of some groups in the population. Overall ... uptake has been fantastic. We're at $80 \%$ already in the over 80 . We're seeing a very strong response.

"But a combination of access, systematic efforts to misinform and lie about the vaccination programme targeted particularly at minority populations, and in some cases longstanding mistrust of public services is standing in the way of people coming forward."

He said that the NHS was putting in place a range of measures to try to ensure equitable uptake of the vaccine, including collecting data on uptake by ethnicity and making targeted attempts to engage with hard to reach communities.

"We want to make sure that we don't have distortions in uptake," he added. "Uptake figures-while protecting people's confidentiality-are now being shared at a small area level with local authority directors of public health so that they can do the great work which they are well known for, engaging with local communities, with faith leaders, community groups, and others to encourage uptake.

"Secondly, [we are taking] targeted action to address the misinformation using communication channels and people who are trusted in different communities. And then, over and above that, making sure that the places where vaccination can be given are sufficiently accessible and diverse, so that they don't stand in the way of uptake as well."

\section{Vulnerable groups}

Stevens told MPs of the need for a "legitimate discussion" on adding new vaccine priority groups in mid-February, once all over 70 and clinically extremely vulnerable people had been offered their first dose.
He said, "The current proposition is that, once we have offered vaccination to everybody age 70 and above and the clinically extremely vulnerable, then the next group of people would be people who are in their 60 s and $50 \mathrm{~s}$.

"The Joint Committee on Vaccination and Immunisation will have to advise on whether or not there are certain other groups who should at that point also receive priority. People, say, with learning disability and autism; certain key public service workers-teachers, the police-they will all have to be factored in in that post-February 15 prioritisation decision as well."

1 Royal Society for Public Health. New poll finds BAME groups less likely to want COVID vaccine. 16 Dec 2020. https://www.rsph.org.uk/aboutus/news/new-poll-finds-bame-groups-less-likely-to-want-covid-vaccine.html.

This article is made freely available for use in accordance with BMJ's website terms and conditions for the duration of the covid-19 pandemic or until otherwise determined by BMJ. You may use, download and print the article for any lawful, non-commercial purpose (including text and data mining) provided that all copyright notices and trade marks are retained. 